\title{
BPX INSULATION IRRADIATION PROGRAM TEST RESULTS*
}

\author{
T. J. McManamy \\ Oak Ridge National Laboratory \\ Oak Ridge, TN 37831-8053
}

CONF-910968--18

DE92 000739

\author{
G. Kanemoto \\ Idaho National Engineering Laboratory \\ Idaho Falls, ID 83415
}

\section{Abstract}

The toroidal field coil insulation for the Burning Plasma Experiment (BPX) is expected to receive a radiation dose of nearly $10^{10} \mathrm{rad}$ and to withstand significant mechanical stresses. An irradiation test program was performed at the Idaho National Engineering Laboratory (INEL) using the Advanced Technology Reactor (ATR) for irradiations to doses on the order of $3 \times 10^{10} \mathrm{rad}$. The flexure and shear atrength with compression of commercially procured sheet material were $\mathrm{re}$ ported earlier [T. J. McManamy et al., "Insulation interlaminar shear strength testing with compression and irradiation," in Proceedings of the 13th Symposium on Fusion Engineering, 1990, pp. 342-347; "Insulation irradiation test programme for the Compact Ignition Tokamak," Cryogenics, vol. 31, pp. 277-281, April 1991]. A second series of tests has been performed to slightly higher dose levels with vacuumimpregnated materials, glass strand material, and Syaulrad-S sheet samples. Vaculm impregnation with a Shell 9405 resin and 9470 hardener was used to produce bonded copper squares and flexure samples of both pure resin and resin with S-glass. A new test fixture was developed to test the bonded samples in shear without applied compression. The Spaulrad-S flexure samples demonstrated a loss of strength with irradiation, similar to previous results. The pure resin lost nearly all flexibility, while the S-glass-reinforced samples retained between $30 \%$ and $40 \%$ of the initial flexure strength. The S-glass strands showed a $30 \%$ loss of strength at the higher dose level when tested in tension. The bonded copper squares had a low room-temperature shear strength of approximately $17 \mathrm{MPa}$ before irradiation, which was unchanged in the irradiated samples. Shear testing of unirradiated bonded copper squares with ten different types of surface treatment revealed that the low shear strength resulted from the polyurethane primer used. In the later series of tests, the epoxy-based primers and DZ-80 from Ciba-Geigy did much better, with shear strengths on the order of $40 \mathrm{MPa}$. These samples also demonstrated a resistance to cryogenic shock. One irradiated bonded sample was tested up to $210 \mathrm{MPa}$ in compression, the limit of the test fixture, without failure.

\section{Introduction}

A series of tests was carried out to evaluate the shear strength of bonded copper samples after exposure to radiation doses in excess of the the end-of-life requirement for BPX.

\author{
P. G. Snook \\ Prisceton University \\ Princeton, NJ 03540
}

Two capsules were irradiated, one for 20 days and one for 40 days. Each capsule contained 50 bonded samples, a combination of flexure samples of Spaulrad-S sheet material and samples fabricated by impregnating $S$-glass with the Shell 9405 resin/ 9470 hardener system, and also ten strands of silane-treated S-glass. The capsules were approximately 1 in. in diameter and packed with aluminum powder for heat transfer' $O$ the outer surface, which was water cooled. The capsules were welded shut with a normal air atmosphere inside. Surrounding the capsule was a lead shield approximately 1.6 in. thick to reduce the gamma heating. The dose to the insulation was on the order of $2 \times 10^{10}$ rad for capsuie 1 and twice that for capsule 2 with roughly $40 \%$ of the dose from neurons. The fast fluence $(>1.0 \mathrm{MeV})$ was approxirnately $1.7 \times 10^{18} \mathrm{n} / \mathrm{cm}^{2}$ and $3.4 \times 10^{18} \mathrm{n} / \mathrm{cm}^{2}$ for the two dose levels.

\section{Material Selection}

A manufacturing study was performed by the Advanced Technology Division (ATD) at Oak Ridge National Laboratory (ORNL), and vacuum impregnation was selected as the most promising technique to meet the BPX design requirements. Eight different combinations of epoxy resin and hardener were screened in laboratory tests to evaluate handling characteristics, compressive strength, and cryogenic shock resistance. The Shell system was selected because it had the best cryogenic shock resistance with the pot life and low viscosity required for impregnation. In addition, the hardener was an aromatic amins, which was expected to give geod radiation resistance. The system is carcinogenic, however, which complicates handling.

\section{Sample Fabrication}

The bonded samples were fabricated by ATD. The copper was normal silver-bearing hard copper, approximately 3.63 $\mathrm{mm}$ thick, cut into 12.7-mm squares. The surfaces to be bonded were grit blasted using a procedure developed by Princeton Plasma Physics Laboratory (PPPL) for the Tokamak Fusion Test Reactor (TFIR). After git blasting, the surfaces were cleaned and coated with a polyurethane-based primer, Conastic $\mathrm{AD}-20$. The primer was cured at $80^{\circ} \mathrm{C}$ for six hours. $\mathrm{S}-2$ glass cloth with a silane treatment was cut into $12.7-\mathrm{mm}$ squares. Each sample had five layers of cloth between copper pieces, giving a bond thickness of approximately $1 \mathrm{~mm}$. A mold was developed and used for vacuum impregnating 66

\footnotetext{
Research sponsored by the Office of Fusion Energy, U.S. Deparment of Energy, under contract DE-AC05.84OR21400 with Marin Mariera Energy Systems, Inc.
} 
samples at a time. Figure 1 sinows the central mold plate with squares to hold the samples. UFper and lower cover plates with a series of grooves were used to seal the mold and provide a path for resin impregnation. This sample geometry was also chosen to allow future tesing of combined compression and shear on bonded chips. The Shell 9405 resin was used with the Shell 9470 curing agent in a stoichiometric mix ratio of $100 / 28$. The samples were allowed to gel at $80^{\circ} \mathrm{C}$ for 8 to $12 \mathrm{~h}$ and then cured at $120^{\circ} \mathrm{C}$ for $1 \mathrm{~A}$. Three batches were fabricated for testing at INEL. A fourth batch was also fabricated with only four layers of glass; these samples were used at PPPL to evaluate the shear test device described below.

In addition to the bonded samples, sheet sections of resin and sheets of resin with S-glass were fabricated and cut into flexure samples $50.8 \mathrm{~mm} \times 5 \mathrm{~mm} \times 1.5 \mathrm{~mm}$. Spatirad-S 1. $\mathrm{mm}$-thick sheet material was also cut into flexure samples of the same size.

\section{Shear Test Fixfure and Preliminary Testing}

A shear test device for one sample was developed and is shown in Fig. 2. One edge of the sample is suppored on a ledge, and the load is applied on the opposite edge through a pusher block. This block is supponed on the face away from the sample by a piece of low-friction material that prevents rotation but allows vertical motion. Variations in sample thickness are accommodated by a wedge. The wedge surface is at a shallow angie and is designed to lock by friction due to the compressive loads generated by the restraint forces against rotation. A vacuum line is used to hold the sample while the wedge and pusher block are installed. This configuration allow's for very easy insertion of a sample, which is imporant for use with activated chips.

\section{INEL TesL Resulis}

\section{Elexure Testing}

The span length for the lests was $31.8 \mathrm{~mm}$ measured between the centers of 3-mm-radius supports. Six samples of each material were contained in both capsules. The extreme fiber suress at the highest load for control and irradiated samples of Spaulrad-S is shown in Fig. 3. It was noted that the results depended on the orientation of the sample. Higher strengths and slightly lower modulus values were found for control samples with the fill side on the bottom tensile surface. This orientavion was used for the irradiated sample tesung. The asymmetric construction was a result of an odd number of layers (5). The average peak stress of the three control samples w'th the fill side on the bottom was $870 \mathrm{MPa}$. The average loss of strength was $44 \%$ for capsule 1 (20-day exposure) and $54 \%$ for capsule 2 (40-day exposure).

The maximum flexure stress test results for Shell resin with S-glass are also shown in Fig. 3. Some of the irradiated sample failures were in interlaminar shear, rather than flexure. The average control group maximum stress was $558 \mathrm{MPa}$ and the average reduction in strength was $69 \%$ for capsule $l$ and $57 \%$ for capsule 2 .

Fexure samples of pure resin were tested. The control samples showed a very large strain before failure. The irradiated samples, however, lost nearly all flexibility. Five of the six samples in each capsule fractured either during irradiation or during gentle cleaning after irradiation. The samples had tumed completely black and the fracture surfaces appeared glassy. One sample from each capsule was available and was tested in flexure in addition to five control samples. The control group had an average flexure strength of approximately $100 \mathrm{MPa}$, while the flexure strengths of the two samples that survived irradiation were only about 7 and $15 \mathrm{MPa}$. 
(20-day exposure), which had been out of the reactor for six weeks, was approximately $1 R$. The activity of samples from capsule 2 (40-day exposure) was approximately $3 R$. The dominant ccrtribution to the activation was from cobalt

The test results are shown in Fig. 4. The average shear strength for the control group was $17 \mathrm{MPa}$. This was also the average for capsules 1 and 2 . On average, no reduction due to radiation was noted. All failures were at the copper-epoxy interface. Control and irradiated samples were also tested after being "dunked" in liquid nitmgen and w'armed to room temperature. No significant differences were found.

The irradiated epoxy changed color from amber to black. There was no consistent difference between the three fabrication batches.

One bonded sample from capsule 2 was tested in pure compression with the load perpendicular to the flat faces. The plot of deflection versus load was smoath, with no indications of failure up to $275 \mathrm{MPa}$, the limit of the test fuxture.

Fig. 2. Shear test device.

Fig. 3. Maximum flexure stress for Spaulrad.S and Shell resin with S-glass.

\section{Shear Testing}

Five samples from each of three fabrication batches were tested in shear from an unirradiated control group and from the two capsules. The contact activity of samples from capsule 1
Fig. 4. Shear strength.

\section{S-Glass Tensile Strength}

Strands of plain S-2 glass with silane treatment were irradiated in each capsule. Ten strands from each capsule and a control group of ten were tested in tension. Each strand was wrapped around cylinders approximately $16 \mathrm{~mm}$ in diameter separated by approximately $75 \mathrm{~mm}$ on a Tinius Olson tensile test machine. The ultimate stress at failure is shown in Fig. 5. The cross-sectional area was estimated from the measured weight per unit length and the published S-glass density of 2.48 $\mathrm{g} / \mathrm{cm}^{3}$. The average $31 \%$ loss of strength at the higher dose indicates that a threshold for damage has been passed. The activity of the samples was about $0.4 \mathrm{mR}$ for both capsules. 
comparison. Two groups were fabricated using the DZ-80 primer, one of these sets was cured at $250^{\circ} \mathrm{F}$ prior $10 \mathrm{im}$ pregnation as recommended by the vendor, and the second set was cured at $284^{\circ} \mathrm{F}$, as recommended by PPPL based on the experience from TFIR testing.

Fig. 5. S-glass strand tensile strength.

\section{Other Tests}

Because different equipment and personnel were used before and after irradiation for dimensional measurements of flexure samples, two available control samples were remeasured at the hot cell. The results indicated that there was a systematic difference of approximately $0.02 \mathrm{~mm}$ between the measurements made before loading and those made at the hot cell. This difference would cause an apparent shrinkage in thickness on the order of $2 \%$. A correction factor was added to all hot cell measurements for comparison with measurements taken before irradiation. The changes in width, thickness, length, and volume for Spaulrad-S and resin with glass were on the order of $1 \%$ or less and probably within the experimental ertor. The pure resin volume change on average was $-5 \%$ for capsule 1 and $-3.5 \%$ for capsule 2 .

One fiexure sample of each rype was also used to measure density for control and irradiated conditions. The density was measured by weighing the samples in air and in water. Figure 6 shows the results.

The Spaulrad-S and resin densities agree well with published data. The density for the resin + glass implies a glass volume fraction of $40 \%$ based on the S-glass density of $2.48 \mathrm{~g}^{\prime} \mathrm{cm}^{3}$.

\section{PRIMER EVALUATION}

After the shear test results and manner of failure were reviewed, a set of shear samples was fabricated by ATD, using the same resin and procedures as before with a variety of different primers. With one impregnation of the mold, 60 samples were fabricated; there were 10 groups of samples, each containing 6 samples of each type of surface preparation. One group used the AD-20 primer for comparison with the RAD II results. Another group used no primer for a control

Fig. 6. Density measurements.

One set of samples received a surface treatment from PDA Engineering, which developed a method of improved copper-epoxy bonding under a DOE SBIR contract. The other five types of primers were seler ed by $A T D$ after a literature survey. One primer type was th e EBANOL-C chemical treatment based on ihe ASTM procedure. The other four were different types of epoxy-based primers from American Cyanamid, Dexter Hysol, and 3M. A summary is given in Table 1.

After curing, one of the unprimed samples and three of the samples primed with the PDA process failed when they were removed from the mold. The remaining samples were tested in shear on a duplicate of the shear test device used at INEL. Prior to testing, two samples from each group (except for the PDA and unprimed samples ) were dunked in liquid nitrogen and then warmed to room temperature to see if cryogenic shock influenced the sh:aar strengths. The test results are show'n in Fig. 7. Shear strengths as high as $48 \mathrm{MPa}$ were measured with the average of some on the order of 35 to $40 \mathrm{MPa}$. Most samples still failed at the copper-epoxy interface, but several of the samples that failed at the highest loads did have an interlaminar shear failure mode. The epoxy-based primers as a group did well. There was a significant amount of scatter in the data. Examination of samples indicated that the glass did not go to the edges, and this may be pan of the reason for the scatter. Cryogenic shock did not appear to have a significant effect.

\section{CONCLUSIONS}

The measured shear strengths after irradiation were limited by the adhesive strength of the copper-epoxy bond to approximately $17 \mathrm{MPa}$ with the polyurethane primer used. 
The cohesive shear strength of the epoxy systems was $>20$ $\mathrm{MPa}$ and the compressive strength was $>275 \mathrm{MPa}$, even after a dose on the order of $4 \times 10^{10} \mathrm{rad}$. There was a significant amount of scatter in the data, but the results appeared to be independent of radiation dose level within the range tested. Subsequent testing indicates that the interlaminar shear surength of the Shell system is on the order of 40 to $50 \mathrm{MPa}$ prior to irradiation. Cryogenic shock does not appear to have a significant effect. The Shell resin showed a great loss of flexibility due to irradiation damage. The flexwe samples of Shell resin with S-glass did not fail at the strain limit of the pure resin and went to significanty higher strains, although there was a large loss of strength compared to the unirradiated samples.

There appears to be a threshold for damage to the S-glass, and a $31 \%$ loss of strength at the high dose level was observed.
The data on dimensional changes are inconsistent There is no direct agreement between measured changes in dimensions and measurement of volume change based on density calculations from wet and dry weight measurement. There is some indication of shrinkage, but the amount appears to be less than reponed previously.

\section{Acknowledgment}

This repor is the result of the work of a large number of people, including those at ATD who designed the mold and did the screening tests, the hot cell technicians at INEL who performed all the irradiated sample testing, and the Princeton technicians who developed the shear tester and evaluated the primers. Space does not permit a complete list, but speciai thanks are due J. Dooley, J. Hubrig, and C. Janke at ATD, D. Sparks at NEL, and R. Majeski and C. Lindemuth at PPPL.

Table 1. Summary of primer types

\begin{tabular}{|c|c|c|c|}
\hline Identifer & Name & Vendor & Type \\
\hline 1 & $A D-20$ & Conastic, Inc. & Polyurethane-based \\
\hline 2 & Ebanol-C & Ethone, Inc. & ASTM D2651 Method E \\
\hline 3 & $\mathrm{DZ}-80$ & Ciba-Geigy (U.K.) & $\begin{array}{l}\text { Phenol formaldehyde and methylated melamine in methylated } \\
\text { solvent, cured at } 250^{\circ} \mathrm{F}\end{array}$ \\
\hline 4 & BR 127 & American Cyanamid & Epoxy phenolic with corrosion inhibitors \\
\hline 5 & E.A9210H & Dexter Hysol & Epoxy based with corrosion inhibitors \\
\hline 6 & $\mathrm{EC} 3924 \mathrm{~B}$ & $3 \mathrm{M} \mathrm{Co}$ & Epoxy based with corrosion inhibitors \\
\hline 7 & EC3960 & $3 \mathrm{MCo}$ & Epoxy based with corrosion inhıbitors \\
\hline 8 & & & No primer \\
\hline $\mathrm{U}$ & PDA & PDA & Chemical process for copper-epoxy tonding \\
\hline$X$ & $\mathrm{D} Z 80$ & Ciba-Geigy (L.K.) & $\begin{array}{l}\text { Phenol formaldehyde and methylated melamine in methylated } \\
\text { solvent. cured at } 284^{\circ} \mathrm{F}\end{array}$ \\
\hline
\end{tabular}

Fig. 7. Bonded sample shear strength with different pnmers. 

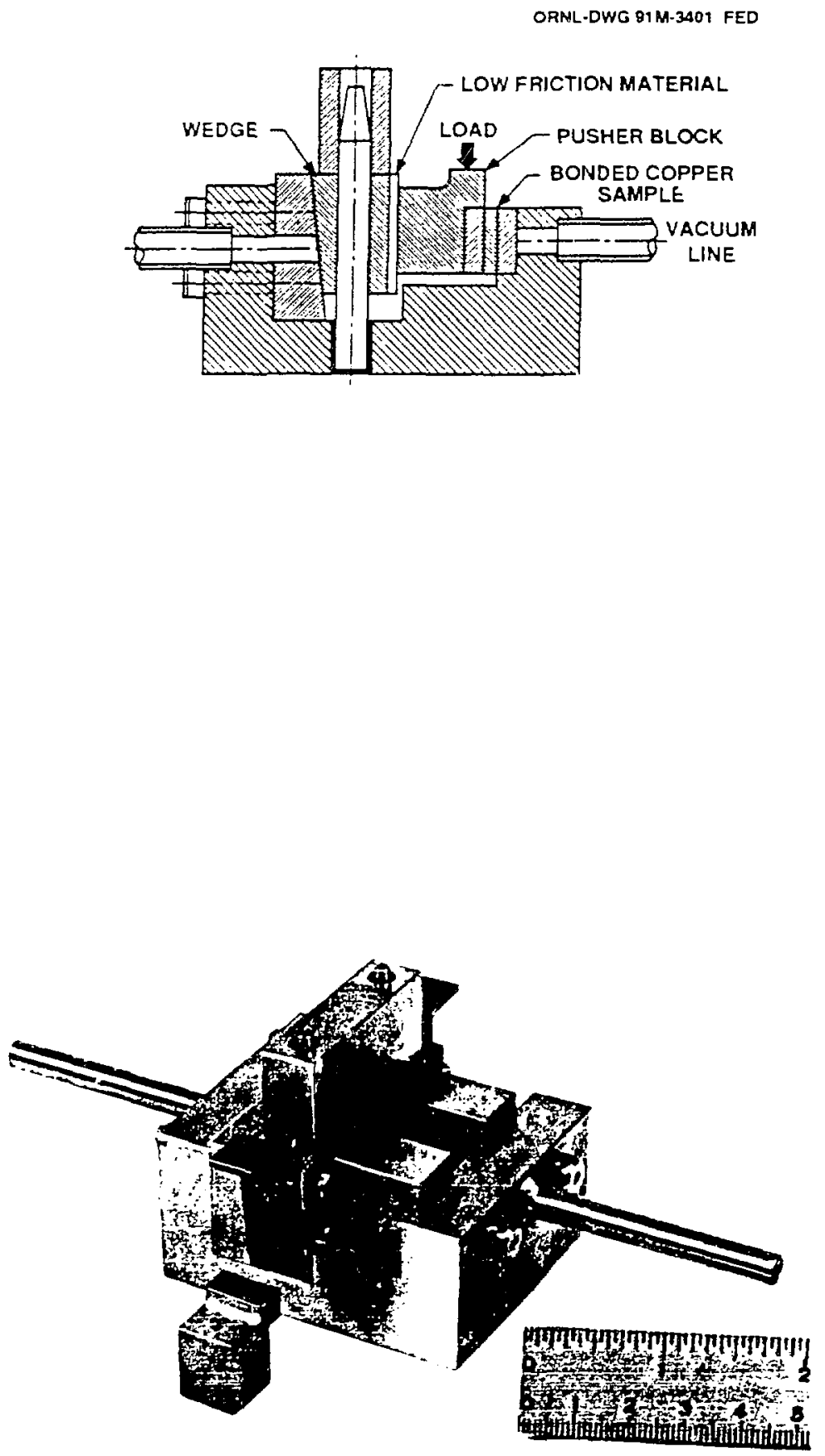


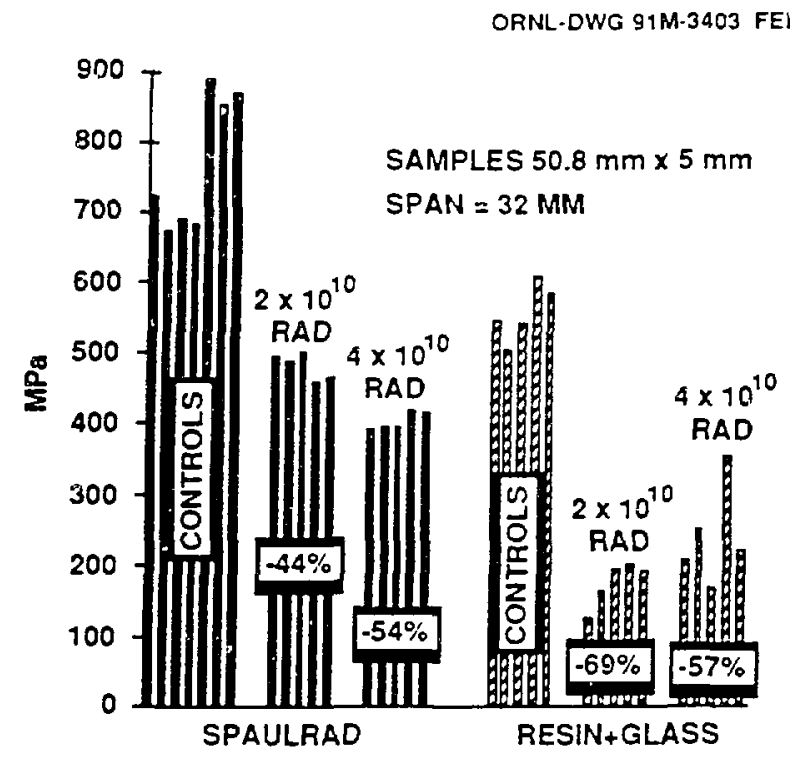





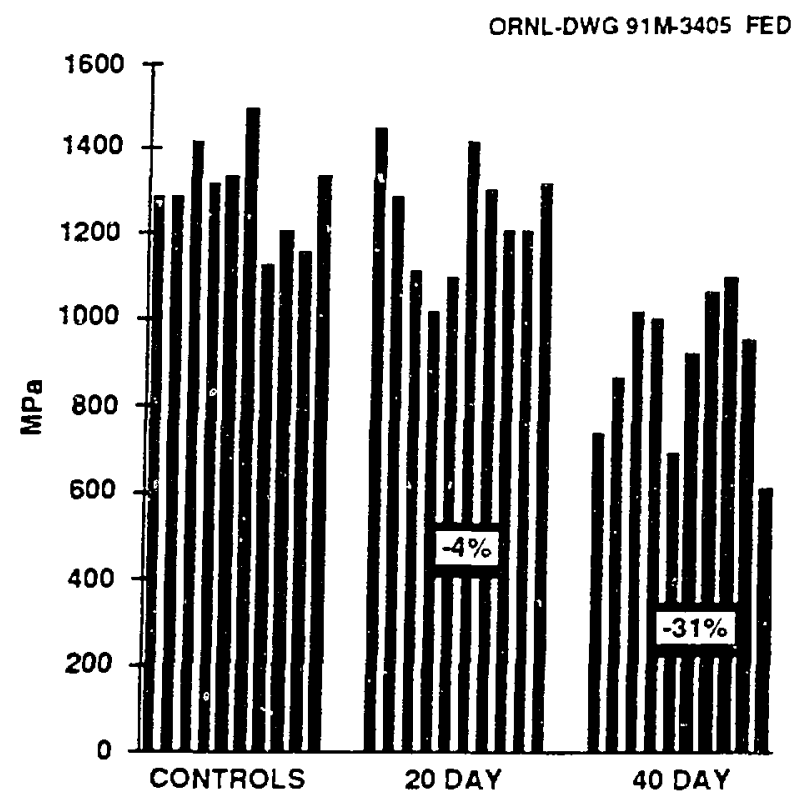




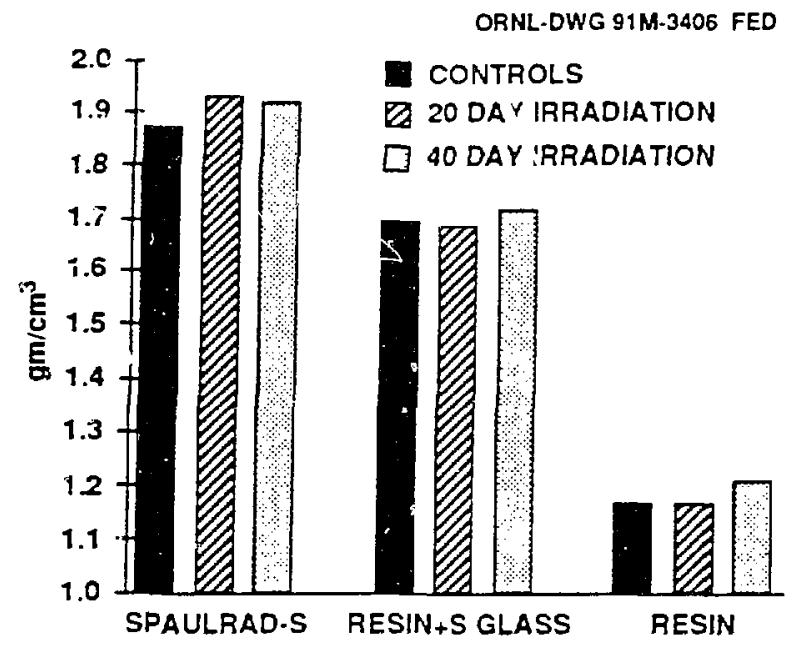




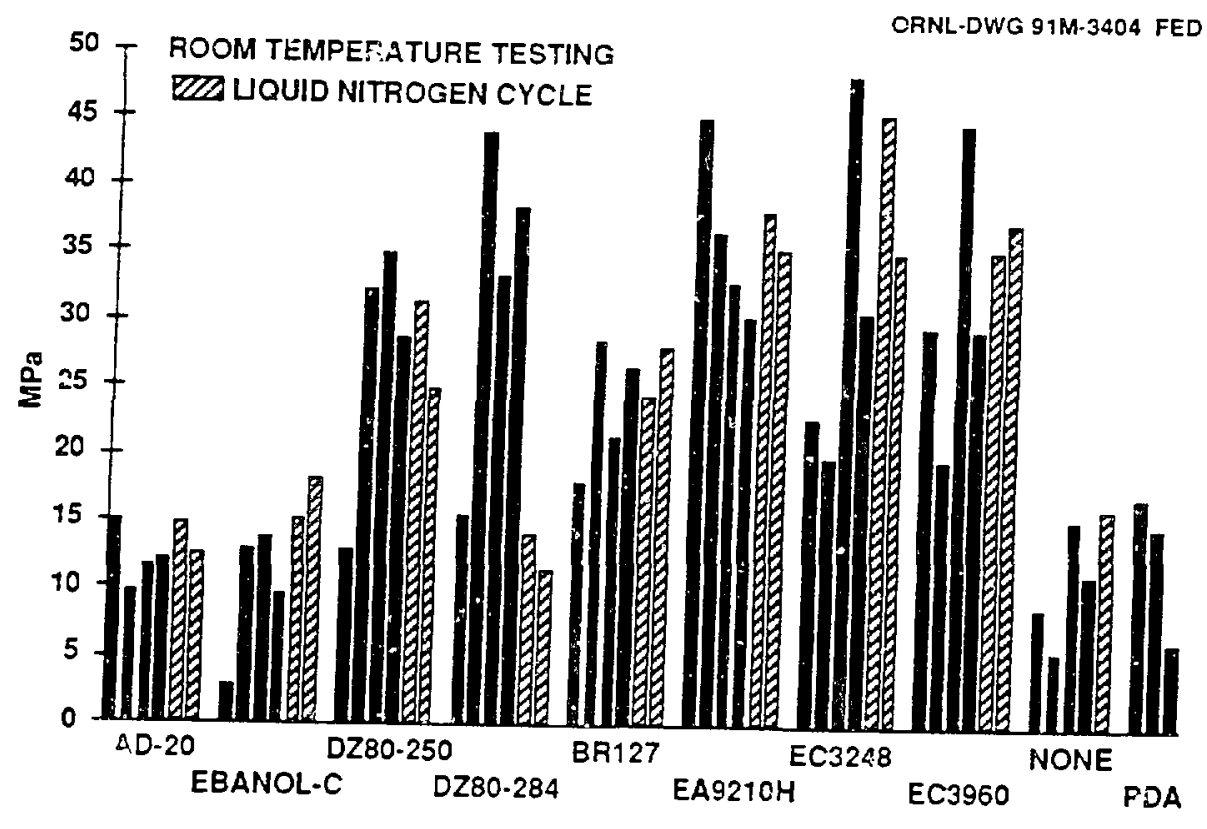

DISCLAIMER

Th1s report was prepared as an account of work sponsored by an agency of the United States Government. Neither the United States Government nor any agency thereof, nor any of their employees, makes any warranty, express or implied. or assumes any legal liability or responsibility for the accuracy, completeness, or usefulness of any information, apparatus, product, or proxess disclosed, or represents that its use would not infringe privately owned rights. Reference herein to any specific commercial product, process. or service by trade name, irademark, manufacturer, or otherwise does not necessarily constitute or imply its endorsement, recommendation, or favoring by the Unted States Government or any agency thereof. The views and opinions of authors expressed herein do not ne -essarily state or reflect those of the United Siates Goyernment or any agency thereof 